\title{
Food Sanitation
}

\author{
BY GLENN G. SLOCUM, Ph.D.
}

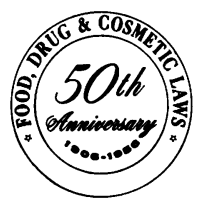

In the first annual report of the Bureau of Chemistry, Department of Agriculture, after the passage of the Food and Drugs Act of 1906 (1), Dr. Harvey W. Wiley stated: "Any unfavorable conditions found in the factories inspected were subsequently discussed with the inspectors, with a view ... of impressing upon them the necessity of sanitation in the preparation of articles of food and drugs ...." Thus, food sanitation programs were initiated at the inception of enforcement of the first Federal food and drug law. They have continued for 50 years to occupy a prominent position in the work of the Food and Drug Administration.

The Food, Drug, and Cosmetic Act of 1938, like the act of 1906 , is basically a statute to protect the public health. Proper sanitation in the production and handling of foods and drugs is one of its major requirements.

A sanitary food, strictly speaking, is one free from injurious substances, particularly infectious micro-organisms. But modern concepts of food control have expanded this definition to include freedom from materials that are repulsive or obnoxious regardless of their importance as agents of disease. This development is an important factor in the protection of health, since many forms of food contamination carry potential health hazards that cannot be measured, even with modern analytical tech-

Dr. Slocum is chief of the Division of Microbiology, Food and Drug Administration. niques, by objective examination of food products. The expanded definition has become generally accepted by the food industries and the public, and it is firmly established by many court decisions in actions brought under the food and drug laws.

The requirements of the law and the objectives of the Food and Drug Administration with respect to food sanitation may be stated simply: that foods be prepared from clean, sound, and wholesome raw materials and that sanitary conditions prevail at all stages of production and distribution. It has been the consistent policy of the Food and Drug Administration through 50 years of enforcement of the food and drug laws to seek to improve the sanitary quality of the food supply by all means and facilities at its disposal.

\section{The Early Activities}

When the Food and Drugs Act was enacted in 1906, interstate traffic in foods was limited primarily to a few staple products. Food production and distribution were largely local operations, and the housewife usually processed the basic raw materials in her home. Although Dr. Wiley and others supporting the drive for legislation were preoccupied with such problems as the use of harmful or potentially harmful chemicals in foods and widespread economic adulteration, writings of that period show that there was a real recognition of and concern with problems of food sanitation.

Early administrative reports of the Bureau of Chemistry, Department of Agriculture-the agency charged with enforcement of the Food 
and Drugs Act until the Food and Drug Administration was created in 1927-clearly trace the development of food sanitation programs (1). Sanitary requirements of the law were stressed in inspection of all food processing and distributing facilities. Field and laboratory investigations of sanitation were soon initiated for many important commodities, including milk, cream, ice cream, bottled mineral waters, shellfish, gelatin, poultry, and fresh, frozen, and dried eggs. Bacteriological and microscopic methods of analysis for detection of contamination and spoilage were developed and put into use. Research operations not only revealed enforcement problems and methods for the detection of contamination but also provided information to help industry avoid violations and improve the overall quality of the product. This educational approach, which has always been coordinated with enforcement of the legal requirements of the food and drug laws, is often unknown to those not fully conversant with the Food and Drug Administration's work.

One of the outstanding personalities in the early food sanitation programs was B. J. Howard, chief of the microchemical laboratory of the Bureau of Chemistry. His applications of the microscope to the detection of decomposed, filthy, or insanitary foods were a major contribution to improvement in the sanitary quality of foods in this country. For the development of a mold count method of detecting rot in tomato products, he received worldwide recognition.

Although the microbiological aspects of food sanitation were an important element of the early investigations, a separate microbiological laboratory was not created in the Bureau of Chemistry until 1913. Under the direction of Dr. Charles Thom, the noted mycologist, the laboratory continued and expanded investigations in food sanitation and spoilage and food poisoning. It was in this laboratory that Dr. Stewart Koser conducted his studies of the metabolism of coliform organisms. His findings form the basis today for distinguishing Escherichia coli from other members of this group. Research in food sanitation was further expanded under Dr. A. C. Hunter, who became director of the bacteriology laboratory when the Food and Drug Administration was created in 1927. Drs. Thom and Hunter were authors of the book "Hygienic Fundamentals of Food Handling," published in 1924. It was one of the earliest books, if not the first, on this subject.

\section{Improvements in the Law}

The Food and Drugs Act of 1906 defined a food as adulterated "if it consists, in whole or in part, of a filthy, decomposed, or putrid animal or vegetable substance . . . ." This was the legal basis on which the food sanitation programs were founded. Although major improvements resulted from application of this requirement, there was early recognition of serious limitations of the law. This is best summed up by the following statement from the 1933 Report of the Food and Drug Administration by Walter G. Campbell (1):

"One of the most serious limitations of the present law, of especial moment where public health questions are involved, is the lack of control of insanitary practices in food-manufacturing plants. Jurisdiction under the Federal statute exists only after a product has been shipped or offered for shipment within the scope of the law. The detection of insanitary practices through inspection in the manufacture of food products does not give sufficient warrant for removing offending goods from interstate channels. To obtain evidence of contamination that will warrant a charge of adulteration within the meaning of the law, it is necessary to collect representative samples of the product and analyze them. This is by no means always an easy matter. Analytical methods have not been developed with that degree of refinement needful to establish in all instances evidences of insanitary handling of a product originating in an insanitary factory."

This important gap in the law was corrected in the Food, Drug, and Cosmetic Act of 1938. It defines food as adulterated-

"If it consists in whole or in part of any filthy, putrid, or decomposed substance, or if it is otherwise unfit for food; or

"If it has been prepared, packed, or held under insanitary conditions whereby it may have become contaminated with filth, or 
whereby it may have been rendered injurious to health. ..."

Other requirements of the 1938 law or its amendments made factory inspection mandatory and extended jurisdiction to articles adulterated while held for sale (whether or not the sale is the first one) after shipment in interstate commerce.

These changes gave the Food and Drug Administration legal authority to deal comprehensively with food sanitation.

\section{Enforcement Procedures}

The 50 years of food law enforcement coincides with the period of vast expansion of the food industries. Increasingly, food production has moved to large factories which distribute products throughout the Nation. Often the products have been so altered in form that the consumer has little basis on which to judge their original cleanness and wholesomeness. As the more obvious forms of adulteration disappeared, newer, more subtle forms became apparent. These have required development of new techniques for their detection.

To provide for the most effective and efficient use of the limited funds and facilities available to deal with the increasing needs for consumer protection, the project system of operations was introduced in 1922. In brief, this system consisted in the formulation of a comprehensive and unified plan of operations for the entire field force, directed against specific classes of products that experience had shown to be most likely to be in violation. Priorities were assigned for work allocations in the following order :

1. Violations involving danger to health.

2. Offenses against decency (insanitation, filth, and decomposition).

3. Economic adulteration.

The project system is the basic pattern for the regulatory programs of today, including the programs in food sanitation.

In order to determine the types, sources, and routes of transmission of contamination, a knowledge of methods of production, processing, packaging, and marketing is necessary. This information is obtained through broad investigations of an industry in various locali- ties by inspectors of the field force, usually in collaboration with technical experts from the Washington headquarters. With this background, inspectional and laboratory techniques are devised, policy is determined, and a plan of action is issued for uniform application throughout the country.

The basic operation in a food sanitation program is the sanitary inspection of the factory. The likelihood that food may be polluted or contaminated with filth in the factory is in proportion to the distance between the filth and the product under preparation. The objective of the sanitary inspection is to measure this distance in terms of space, time, opportunity for pollution or contamination, and vehicles of transmission.

An establishment operating in a manner to invite, or permit, contamination of food with foreign matter properly classified as filth is insanitary. The objectionable matter may be the excreta of man or animal, or it may be flies, maggots, worms, insects or insect parts, rodent hairs, or other such material.

In many instances, the contaminants are macroscopic, and detection of the avenues of their entrance into food depends only on keen powers of observation and common sense. In other instances, the contaminants are micro-organisms or microscopic filth, and knowledge and appreciation of invisible routes of distribution are required.

Sanitary inspection evidence alone, presented in court by the inspector, often with pictures and exhibits demonstrating insanitary conditions, is sufficient to support a charge that the product "may have become contaminated with filth." Such action is essential in instances in which the objective evidence of even gross contamination has been removed or destroyed by such processes as filtration or pasteurization of the product. More commonly, however, insanitary conditions result in contamination that can be detected in the finished product by bacteriological or microscopic examination.

In practice, then, products shipped from an insanitary establishment are usually sampled in interstate commerce for laboratory analysis. The findings may confirm the inspection evidence of insanitation and establish the presence of filth in the product. Offending products 
Figure 1. Establishments engaged in distribution of products subject to regulation by the Food and Drug Administration.

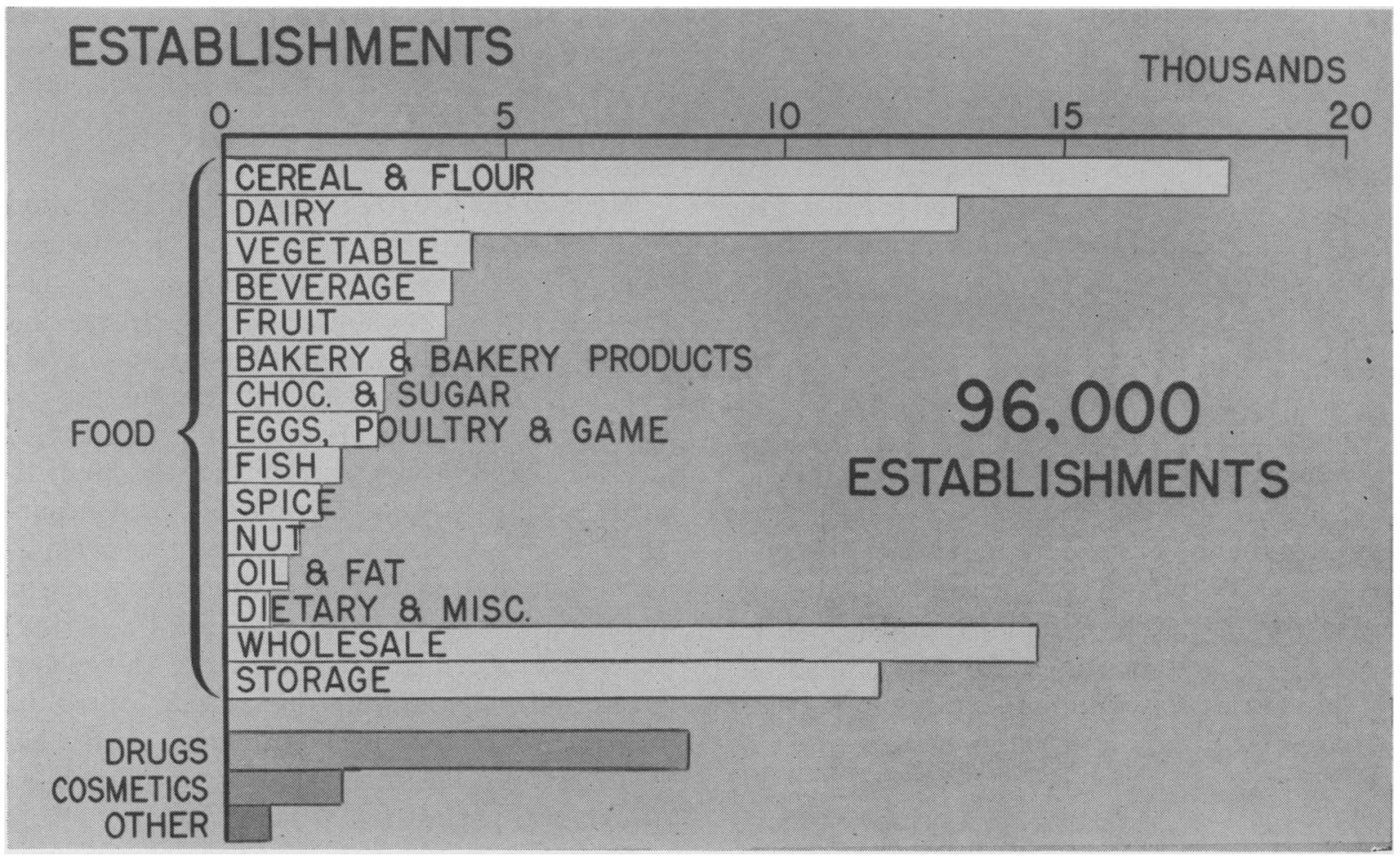

may be removed from the market through seizure by the Federal courts, and the shipper may be prosecuted for, or enjoined from, violating the sanitary requirements of the law.

\section{Voluntary Correction}

Application of these techniques on an industrywide basis, within the limits of funds and facilities, exerts a strong corrective influence. Correction depends on education, and education is inherent in enforcement of the food sanitation requirements. The basic investigations essential to development of a food sanitation program are usually conducted widely in the affected industry. Methods developed to detect contamination are made available to industry for use in preventing contamination. The food and drug law now requires that the FDA inspector give to the agent in charge of the establishment a written report of conditions or practices that might lead to violations of the sanitary requirements of the law. Prior to this amendment, the inspectors discussed with management any such conditions so that voluntary corrective measures might be instituted.
The Food and Drug Administration also promotes voluntary compliance with the law by such means as talks to trade groups, surveys, consultations, and, whenever practicable, direct assistance in solving technical problems. Punitive action under the law then, falls largely on operators who are careless or who are unwilling to use the measures available to them to avoid violations.

It has been stated that the food and drug laws, and particularly the "insanitary conditions" clause in the definition of adulterated foods, have been major stimuli to improvement in food sanitation (2). Certainly this new provision focused attention on a phase of food handling not well attended to by some industries in the past. The response to this provision by the food industries has been gratifying. There are few trade associations or large operators in the food field that are not now active in programs to improve sanitation.

\section{Need for Expansion}

Despite the progress that has been made, there is a serious need for expansion of all food 
sanitation programs-national, State, and local. As shown in figure 1, there are some 96,000 establishments in this country distributing products subject to the Federal food and drug law, the vast majority of which are in the food field. In addition, food and drug imports are subject to the same requirements. There are sanitation problems of greater or lesser degree connected with all the food commodity groups listed. About 10 percent of the establishments can be inspected and about 7 percent of the imports can be sampled each year with the present staff (fig. 2).

The major food sanitation programs of the Food and Drug Administration have been concerned with certain cereal products, butter and cheese, certain fruit and vegetable products, bakery products, confectioneries, eggs, and certain fish products. Current emphasis is on edible oils and poultry. Many commodities within these groups and others in figure 1 have not received organized action with respect to sanitation.

During fiscal year 1955, an average of about 75 tons a week of insect-infested, rodent-defiled, or decomposed food was seized under the food and drug law and removed from trade chan- nels. More than four-fifths of all food seizures fall in these categories. Though a substantial proportion of the food becomes contaminated while it is in wholesale or storage warehouses apart from the point of production, too frequently contamination occurs during production.

Much of the progress in food plant sanitation under FDA programs has been based on the elimination of the more obvious sources of contamination: insects and rodents. Inspection techniques for their detection are relatively simple, and laboratory procedures for the detection and isolation of insect and rodent filth in food have been available for the past 15 years. Emphasis on these factors has encouraged remarkable improvement in (a) surroundings, structure, maintenance, and operation of plants and equipment; (b) cleanliness and soundness, sorting and storing, of raw materials; and $(c)$ plant and laboratory control of raw materials and finished products. It has led to the establishment of sanitary programs as an integral part of food production.

Except in those instances in which contamination with micro-organisms has resulted in clear evidence of danger to health, little has

Figure 2. The scope of accomplishments of the Food and Drug Administration, fiscal 1954.

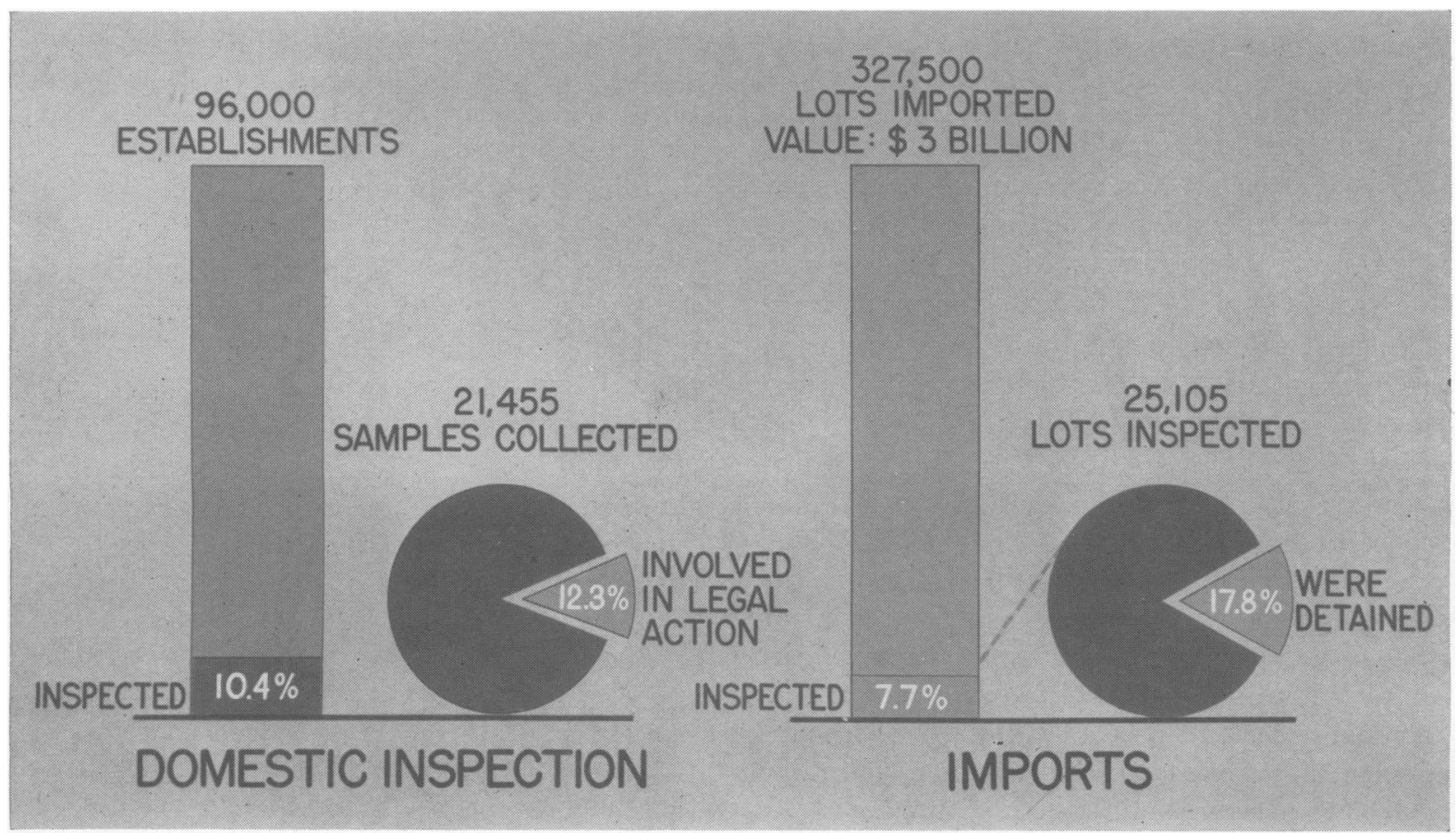




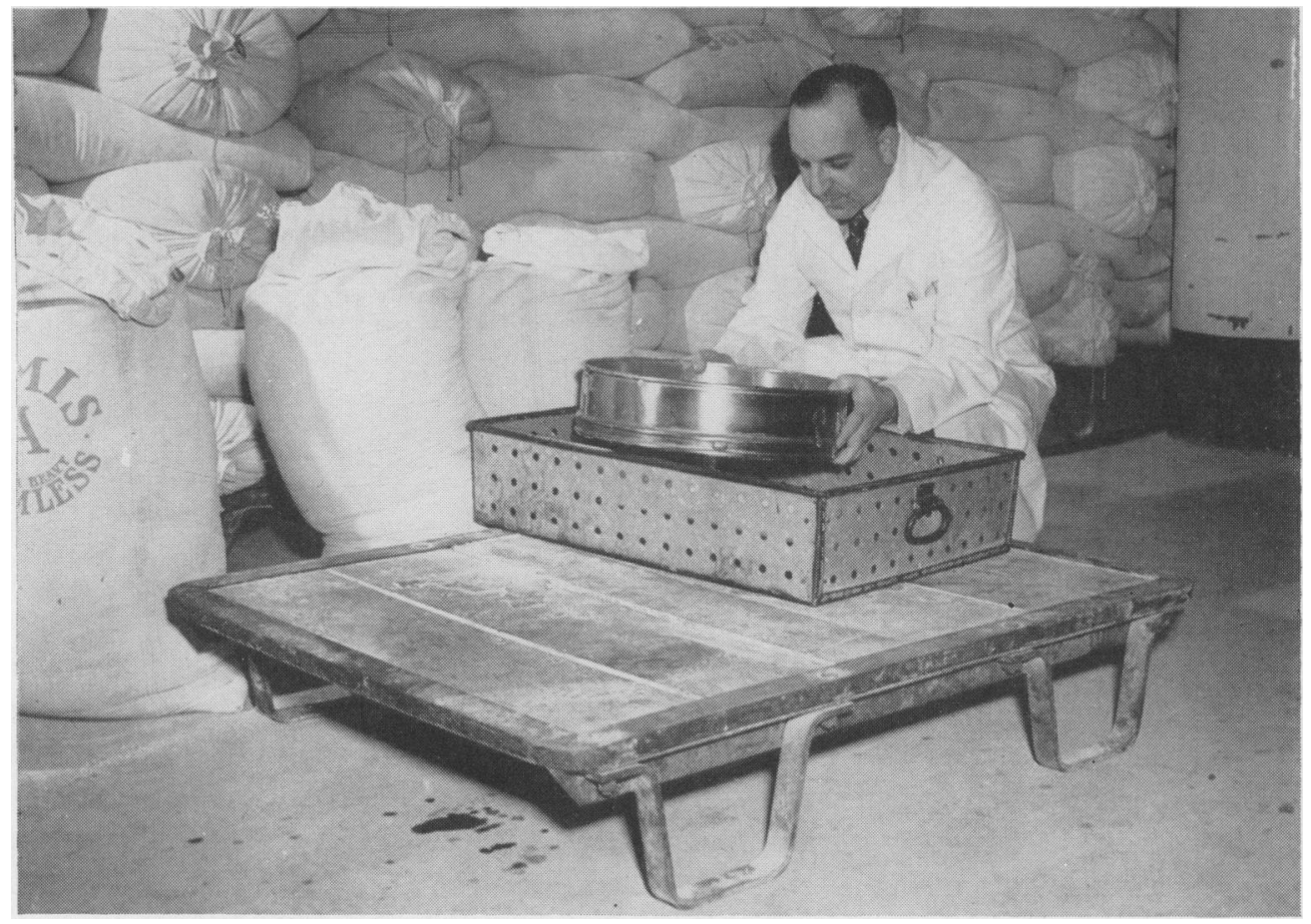

Bakery warehouse flour being examined by FDA inspector for insect infestation.

been done, or can be done with the staff available, in the bacteriological aspects of food plant sanitation. Foodborne infections and intoxications have not decreased in recent years as have waterborne and milkborne diseases. Much of the foodborne disease probably results from mishandling at the point of consumption. But it may well be that there is more bacterial contamination of foods shipped in interstate commerce than is generally realized. Since the enteric infections transmitted by foods must be regarded essentially as evidence of fecal contamination, the importance of improved sanitation during all stages of food production and handling becomes apparent. A much enlarged complement of microbiologists in the FDA field offices is needed to meet the problems in this area.

The Food and Drug Administration has broad responsibility for the protection of the public against interstate traffic in insanitary foods. As new food products, increasingly in processed ready-to-eat forms, appear on the market, expansion of the Food and Drug $\Lambda \mathrm{d}$ ministration of the order recommended by the Citizens Advisory Committee will be neces- sary to cope with the many new food sanitation problems (3).

Many foods, of course, are sold within the community or the State in which they are produced. Sometimes manufacturers having difficulties with the Food and Drug Administration purposefully restrict the distribution of their products to intrastate traffic. Sanitation of these foods is the problem of State and local officials.

Food sanitation, then, is the concern of State and local officials as well as national officials. The combined efforts of all are necessary to afford the degree of protection from insanitary food the consumer expects and is entitled to.

\section{REFERENCES}

(1) Food Law Institute: Federal food, drug, and cosmetic law administrative reports, 1907-1949. Food Law Institute Series, Chicago, Commerce Clearing House, 1951.

(2) Parker, M. E.: Food-plant sanitation. Ed. 1. New York, N. Y., McGraw-Hill, 1948.

(3) Citizens Advisory Committee on the Food and Drug Administration: Report to the Secretary of Health, Education, and Welfare. House Document No. 227, 84th Cong., 1st sess. Washington, D. C., U. S. Government Printing Office, 1955. 